Terbit online pada laman web jurnal: http://jurnal.iaii.or.id

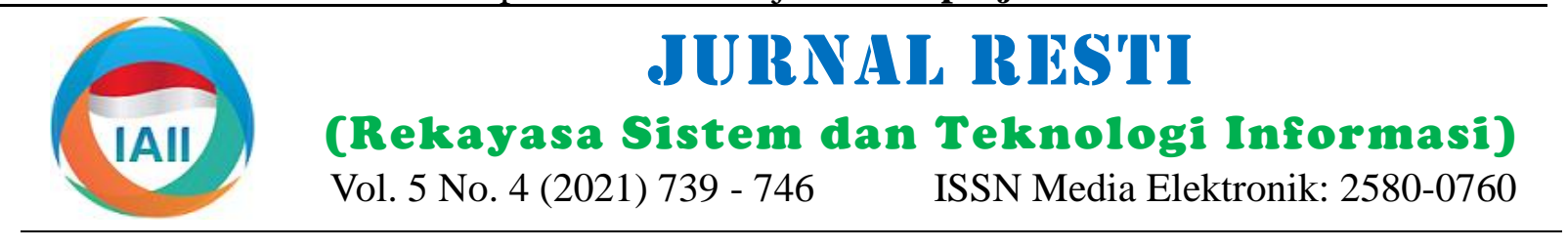

\title{
Desain Sistem Akuisisi Kecepatan Angin pada Menara SST Berbasis IoT
}

\author{
Rachman Rohendi ${ }^{1}$, Herry Sujaini ${ }^{2}$, Redi R. Yacoub ${ }^{3}$, Bomo W. Sanjaya ${ }^{4}$, Purwoharjono ${ }^{5}$ \\ 1,2,3,4,5 Teknik Elektro, Teknik, Universitas Tanjungpura \\ ${ }^{1}$ rachman@student.untan.ac.id, ${ }^{2}$ hs@ untan.ac.id, ${ }^{3}$ rediyacoub@yahoo.com, ${ }^{4}$ bomo.wibowo@ee.untan.ac.id, \\ ${ }^{5}$ purwoharjono@gmail.com
}

\begin{abstract}
Wind energy is one of the new renewable energy sources that can be used to generate electricity. The application of microgrids is expected to reduce the use of fossil fuels. PT PLN UP3B West Kalimantan has a greenfield type SST (Self Support Tower) communication tower with a height of 52 meters. This study aims to test the wind speed acquisition system in real-time on the SST tower. This research was conducted because there is no research on the design of the wind speed acquisition system on the SST Tower. Wind speed measurement data is obtained from the anemometer sensor mounted on the top of the SST Tower. The wind speed measurement data is sent to the MQTT broker and database using the MQTT protocol with the help of a microcontroller and communication media so that the measurement data can be monitored in real-time using the Grafana application either through local or public networks. The study was conducted from February 6 to 27, 2021. As a result, the wind speed data acquisition system managed to collect 5,501,689 wind speed measurement data stored in the database with an average wind speed of $3.03 \mathrm{~m} / \mathrm{s}$.
\end{abstract}

Keywords: wind speed, SST, IoT, MQTT

\begin{abstract}
Abstrak
Energi angin merupakan salah satu sumber energi baru terbarukan yang dapat dimanfaatkan sebagai pembangkit tenaga listrik. Seperti diketahui saat ini pemanfaatan energi angin di Indonesia belum begitu optimal khususnya di kota Pontianak. Untuk suplay listrik di kota Pontianak, bersumber dari grid khatulistiwa dengan mayoritas pembangkit dengan energi fosil. Penerapan mikrogrid diharapkan dapat menurunkan penggunaan bahan bakar fosil. PT PLN UP3B Kalbar memiliki tower komunikasi tipe SST (Self Support Tower) jenis greenfield dengan ketinggian 52 meter. Perlu dibuat alat pengukur kecepatan angin pada puncak tower untuk mengetahui kecepatan angin pada ketinggian 52 meter pada tower komunikasi. Penelitian ini bertujuan untuk menguji sistem akuisisi kecepatan angin secara realtime pada menara SST. Penelitian ini dilakukan dikarenakan belum adanya penelitian mengenai desain sistem akuisisi kecepatan angin pada Menara SST. Data pengukuran kecepatan angin didapat dari sensor anemometer yang dipasang pada puncak Menara SST. Kemudian data pengukuran kecepatan angin dikirim menuju broker MQTT dan database menggunakan protokol MQTT dengan bantuan mikrokontroler serta media komunikasi sehingga data pengukuran dapat dipantau secara realtime dengan menggunakan aplikasi Grafana baik melalui jaringan lokal maupun publik. Penelitian dilakukan dari tanggal 06 februari s/d 27 mei 2021. Hasilnya sistem akuisisi data kecepatan angin berhasil mengumpulkan data pengukuran kecepatan angin sebanyak 5.501 .689 yang tersimpan pada database dengan kecepatan angin rata-rata sebesar $3,03 \mathrm{~m} / \mathrm{s}$.
\end{abstract}

Kata kunci: kecepatan angin, SST, IoT, MQTT

\section{Pendahuluan}

Indonesia saat ini tengah gencar untuk menambah bauran energi baru terbarukan dalam upaya menekan penggunaan energi fosil yang diprediksi akan segera habis. Selain itu isu pemanasan global menjadi isu dunia yang terus digaungkan negara-negara di dunia terutama negara maju yang sadar akan bahaya dari pemanasan global. Energi angin adalah salah satu energi alternatif Berdasarkan buku outlook energi tahun 2019 yang dirilis yang dapat dikembangkan untuk selanjutnya dapat oleh kementrian ESDM, Indonesia memiliki potensi dimanfaatkan sebagai salah satu sumber energi baru terbarukan. Saat ini pemanfaatan energi angin di Indonesia masih sangat minim, sehingga peluang untuk mengembangkan dan pemanfaatan energi angin dapat terus didorong agar Indonesia dapat segera terlepas dari ketergantungan akan energi fosil yang harganya cendrung meningkat dari tahun ketahunnya.

Diterima Redaksi: 19-07-2021 | Selesai Revisi: 14-08-2021 | Diterbitkan Online: 21-08-2021 
energi baru terbarukan yang cukup besar. Total potensi Untuk mencari sumber-sumber potensi energi baru energi baru terbarukan yang dimiliki oleh Indonesia terbarukan perlu dilakukan penelitian potensi energi ekuivalen $442 \mathrm{GW}$ digunakan untuk pembangkit listrik angin pada elevasi di atas 40 meter. Menara komunikasi dimana 60, $6 \mathrm{GW}$ merupakan potensi yang berasal dari jenis SST (self-support tower) merupakan suatu Energi Angin [1].

Energi angin telah digunakan atau dimanfaatkan oleh manusia sebagai sumber energi sejak ratusan tahun lalu, sebagai contoh pada masa sebelum adanya mesin diesel atau mesin uap, para pelaut menggunakan energi angin sebagai sumber energi untuk menggerakan kapal, memanfaatkan angin darat untuk pergi kelaut kemudian untuk kembali ke darat para pelaut memanfaatkan hembusan angin laut untuk membawa kapal kembali ke darat. Kemudian dibeberapa negara, energi angin dipergunakan untuk sebagai alat untuk memompa air. Berkaca dari sejarah Pemanfaatan energi angin sebagai sumber energi merupakan hal yang sangat mungkin dilakukan, ditambah dengan teknologi yang semakin berkembang serta biaya produksi turbin angin dan aksesorisnya yang semakin terjangkau tentu saja
pemanfaatan energi angin perlu didorong lebih masif sebagai upaya untuk mengurangi ketergantungan akan energi fosil.

Pontianak merupakan ibu kota provinsi Kalimantan Barat yang terletak di garis khatulistiwa, sumber utama kelistrikan kota Pontianak berasal dari grid Khatulistiwa yang mayoritas pembangkit di suplai pembangkit listrik tenaga fosil. Untuk mengurangi ketergantungan Kemajuan teknologi telah membantu manusia terhadap energi fosil perlu dicari potensi-potensi apa memudahkan aktifitasnya. Salah satu buah hasil saja yang dapat dimanfaatkan untuk pembangkit listrik kemajuan teknologi adalah IoT. Internet of thing ramah lingkungan. Mikrogrid merupakan sistem merupakan alat yang digunakan untuk memperluas kelistrikan masa depan dimana energi baru terbarukan koneksi internet [6], internet of thing disebut juga merupakan sumber energi utama. Kedepan diharapkan pertumbuhan jaringan untuk menghubungkan kota Pontianak dapat mempersiapkan untuk perangkat-perangkat [7]. Telah dilakukan penelitian merealisasikan sistem mikrogid. Langkah awal yang pengukuran kecepatan angin berbasis web dengan dapat dilakukan untuk merealisasikannya adalah dengan menggunakan raspberry [8]. Pada penelitian tersebut melakukan penelitian-penelitian terhadapat potensi alat pengukur kecepatan angin menggunakan angka energi baru terbarukan, diantaranya energi angin, dummy dan belum menggunakan sensor anemometer matahari dan energi baru terbarukan lainnya.

Letak kota Pontianak berada pada garis khatulistiwa sehingga potensi energi angin di daerah Pontianak tidak terlalu besar. Sudah dilakukan beberapa penelitian yang dilakukan untuk mengukur kecepatan angin di kota Pontianak, kecepatan rata-rata angin yang bertiup di Kota Pontianak termasuk dalam golongan angin rendah, yaitu berkisar pada kecepatan 2,5 - 3,5 m/s[2], $2-3$ $\mathrm{m} / \mathrm{s}$ [3], dan juga telah dilakukan penelitian kecepatan angin di beberapa provinsi di Kalimantan barat dengan menggunakan data angin pada ketinggian 10 meter diatas permukaan laut[4]. Pada penelitian-penelitian tersebut metode pengambilan data angin dilakukan pada elevasi 10 meter di atas permukaan laut, belum ada penelitian tentang potensi energi angin khususnya pada daerah sekitar Kota Pontianak yang dilakukan pada elevasi di atas 10 meter pada permukaan laut.

yang didapatkan dari hasil pengukuran real. Selanjutnya telah dilakukan penelitian pembuatan prototype sistem informasi cuaca berbasis IoT dimana didalam sistem tersebut terdapat sensor anemometer [9][10]. Pada penelitian tersebut penelitian dan pengujian dilakukan hanya sebatas prototype belum dilakukan pengujian pada lingkungan secara real. Kemudian telah dilakukan penelitian tentang rancang bangun sistem kontrol dan monitoring data turbin angin [11][12]. Telah dilakukan implementasi pengukuran kecepatan angin menggunakan sensor JL-FS2 berbasis web untuk mengukur kecepatan angin [13][14][15]. Telah dilakukan penelitian Teknik pengiriman data sensor JLFS2 menggunakan LoRA [16]. Telah dilakukan penelitian tentang alat pengukur angin berbasis Arduino dengan penyimpan menggunakan memory internal [17]. Belum ada penelitian desain sistem akuisisi kecepatan angin pada menara SST. Pada penelitian ini pengujian sistem akuisisi kecepatan angin dilakukan lebih dari 3

DOI: https://doi.org/10.29207/resti.v5i4.3307

Lisensi: Creative Commons Attribution 4.0 International (CC BY 4.0) 
bulan sedangkan penelitian sebelumnya hanya dilakukan beberapa hari saja.

Penelitian ini bertujuan untuk mendapatkan dan menguji desain sistem akuisisi kecepatan angin pada Menara SST greenfield ketinggian 52 meter. Sistem akuisisi ini dibuat untuk mengukur kecepatan angin sehingga data kecepatan angin dapat dipantau secara realtime dan tersimpan pada database. Hasil pengukuran kecepatan angin dapat dimanfaatkan untuk berbagai kepentingan penelitian lain seperti menghitung potensi energi angin dan juga sebagai variable beban angin dalam menghitung kekuatan Menara SST [18]. Selain itu faktor keselamatan manusia menjadikan tujuan lain penelitian ini, karena jika pengukuran kecepatan angin dilakukan secara manual dengan menggunakan anemometer portable pada ketinggian 52 meter, risiko kecelakaan pada saat pengukuran sangat tinggi dan data yang diperoleh dari hasil pengukuran menggunakan anemometer portable terbatas.

\section{Metodologi}

Lokasi penelitian dilakukan pada menara SST greenfield ketinggian 52 meter milik PT PLN UP3B Kalbar. Gambar 1 menunjukan menara komunikasi dimana pada puncak menara dipasang sensor kecepatan angin atau anemometer.

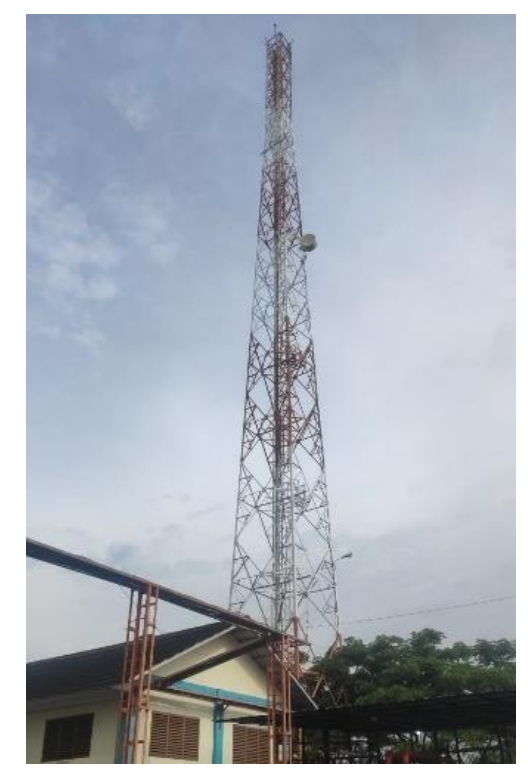

Gambar 1. SST greenfield milik PLN UP3B Kalbar

Penelitian dimulai dengan pembuatan sistem, kemudian dilanjutkan dengan pengujian sistem, jika sistem berhasil mengukur kecepatan angin dan data kecepatan angin dapat tersimpan pada database serta dapat dimonitor secara realtime baik pada jaringan lokal maupun public. Setelah itu dilanjutkan dengan pengumpulan data kecepatan angin. sebagaimana ditujukan flowchart pada Gambar 2.

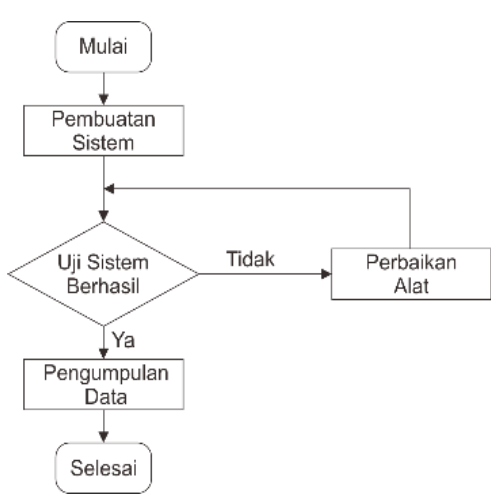

Gambar 2. Flowchart Penelitian

\subsection{Topologi}

Topologi sistem akuisisi data terdiri dari dua sistem yaitu sistem sensor seperti ditunjukan Gambar 3 dan sistem server seperti ditunjukan Gambar 5, jarak antara sistem sensor dengan sistem server adalah 120 meter. Kabel fiber optic jenis drop core digunakan sebagai media komunikasi penghubung kedua sistem tersebut.

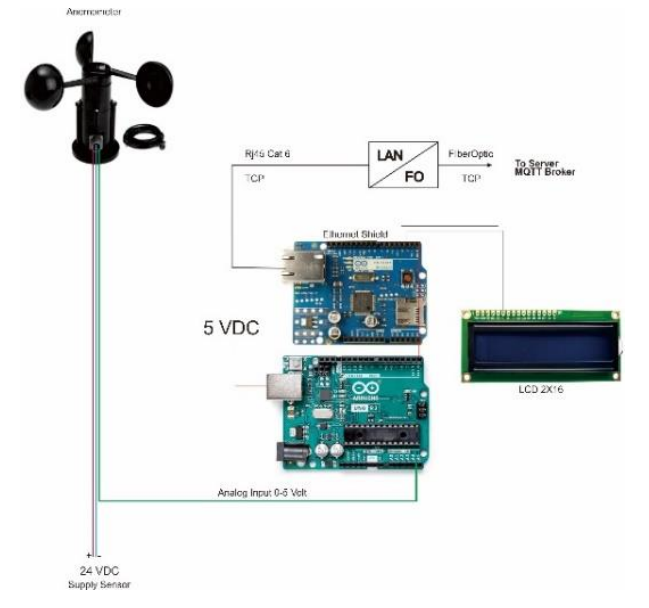

Gambar 3. Sistem Sensor

Sistem sensor terdiri dari peralatan-peralatan seperti sensor kecepatan angin (anemometer), modul mikrokontroler, kabel kontrol dan kabel konverter FO to LAN. Kabel kontrol berfungsi untuk sensor anemometer yang berada dipuncak menara SST dengan modul mikrokontroler yang berada di kaki menara SST. Konverter FO to LAN digunakan untuk mengubah transmisi data media UTP menjadi media fiber optic.

Untuk Sensor yang digunakan untuk melakukan pengukuran kecepatan angin menggunakan sensor jenis JL-FS2 seperti ditujukan pada Gambar 4. JL-FS2 merupakan sensor angin yang memiliki range pengukuran $0-30 \mathrm{~m} / \mathrm{s}$, dengan tegangan output pengukuran 0-5 Volt, error $\pm 3 \%$ dan terbuat dari material aluminium alloy sehingga tahan karat [19]. 


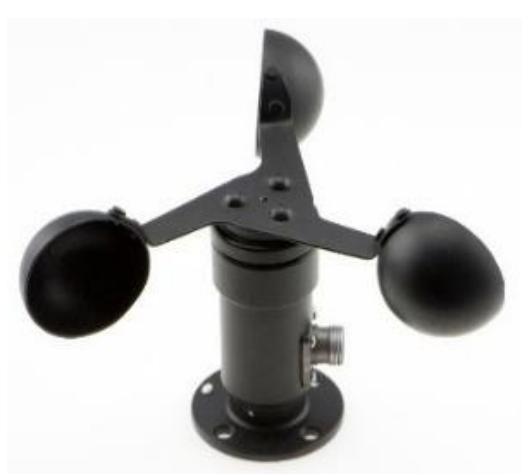

Gambar 4. JL-FS2 [19]

Komputer yang digunakan untuk sistem server menggunakan prosesor intel xeon dengan memory sebesar 16 GB. Operasi sistem yang digunakan adalah Microsoft windows server 2016. MySQL digunakan sebagai aplikasi database yang akan menyimpan data hasil pengukuran kecepatan angin. Untuk GUI menggunakan Grafana.

MQTT merupakan protokol komunikasi publish/subscribe topic-based yang didesain untuk Grafana adalah perangkat analisis dan visualisasi metrik komunikasi dengan menggunakan bandwidth yang berbasis open source. Grafana paling sering digunakan rendah maupun latecy tinggi. MQTT didesain untuk untuk memvisualisasikan data deret waktu untuk meminimalkan penggunaan bandwidth jaringan dan infrastruktur dan analisis aplikasi. Namun Grafana tidak kebutuhan sumber daya pada perangkat serta pada waktu hanya sebatas hal itu saja, kerap kali layanan digunakan yang sama juga berusaha untuk memastikan keandalan untuk visualisasi sensor industri, pengimplementasian dan kepastian dari pengiriman data. Prinsip yang ada ini Internet of thing (IoT), pengamatan cuaca dan juga memunculkan beberapa ide protokol mengenai pengontrolan proses yang sedang berjalan [20].

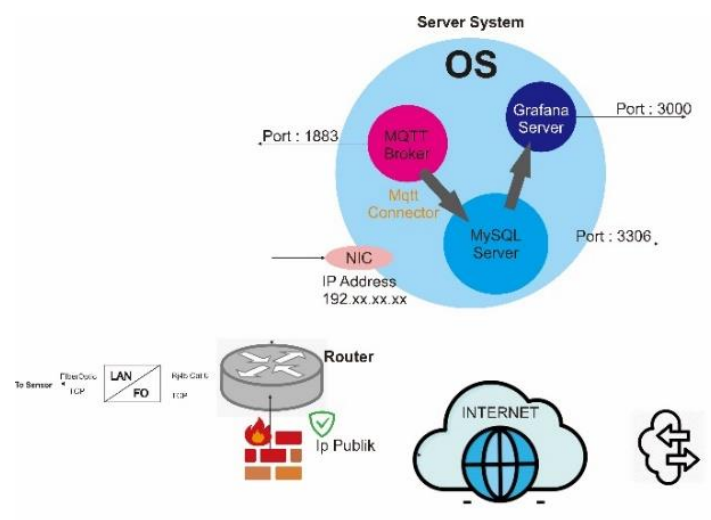

Gambar 5. Sistem Server

"machine-to-machine" (M2M) atau IoT yang menginginkan perangkat di dunia untuk saling terhubung, dan untuk aplikasi mobile dimana bandwidth dan daya baterai pada keadaan yang cukup [21].

Eclipse Mosquitto merupakan broker yang digunakan dalam sistem komunikasi MQTT didalam penelitian ini. Eclipse Mosquitto adalah broker pesan open source (berlisensi EPL/EDL) yang mengimplementasikan protokol MQTT versi 5.0, 3.1.1 dan 3.1. Mosquitto ringan dan cocok untuk digunakan di semua perangkat seperti komputer papan tunggal berdaya rendah hingga server [22]. Gambar 7 Menunjukan proses pertukaran data protocol MQTT. Selanjutnya untuk mengirim data dari broker MQTT menuju ke database dibuat aplikasi MySQL Connector seperti ditunjukan Gambar 8.

\section{of:} menginisiasi library. Data pengukuran dari sensor dikalibrasi menggunakan faktor kali sesuai datasheet. Proses kalibrasi terjadi didalam komputasi mikrokontroler. Data pengukuran dikirim menuju MQTT broker. Data pengukuran pada broker di-insert kedalam database seperti ditujukan pada Gambar 6.

\subsection{Sistem Komunikasi Data}

Modul Ethernet shield digunakan sebagai interface penghubung modul arduino kedalam jaringan TCP/IP. Selanjutnya protokol komunikasi yang digunakan untuk menghubungkan sistem sensor dengan sistem server adalah MQTT (Message Queue Telemetry Transport).

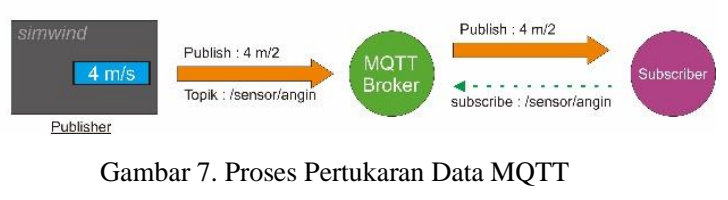

Pada sistem server terdapat Router yang berfungsi untuk menghubungkan jaringan lokal sistem akuisisi dengan jaringan publik atau internet. Sehingga data hasil pengukuran kecepatan angin dapat dimonitor menggunakan device (pc/smartphone/tablet) yang

DOI: https://doi.org/10.29207/resti.v5i4.3307

Lisensi: Creative Commons Attribution 4.0 International (CC BY 4.0) 
terhubung dengan jaringan internet. Firewall dipasang 2.4 Pengujian

bertujuan untuk mengamankan router dari serangan cyber. Sistem akuisisi kecepatan angin secara keseluruhan yang terdiri atas sistem sensor sampai dengan sistem server dapat dilihat pada Gambar 9.
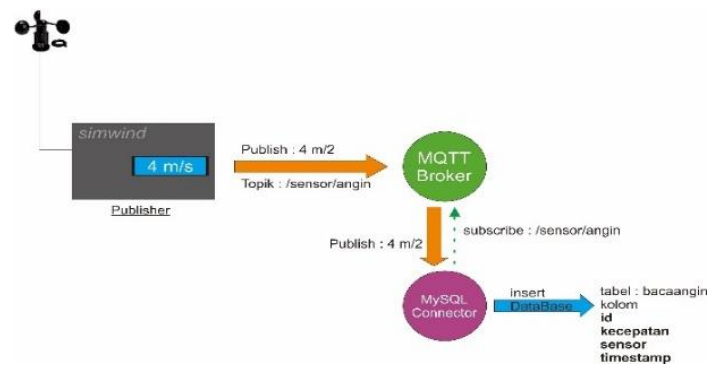

Gambar 8. Insert Database pada MQTT Broker

\subsection{Kalibrasi}

Pada penelitian ini metode kalibrasi yang digunakan adalah dengan menggunakan angka kalibrasi yang ada pada datasheet sensor. Berdasarkan datasheet, data output sensor dapat ditransmisikan melalui kabel lebih dari 1000 meter. Diketahui bahwa jarak sensor menuju modul Arduino pada penelitian ini adalah 60 meter, atas dasar tersebut kalibrasi dapat menggunakan nilai yang terdapat pada datasheet pabrikan sensor. Tabel 1 Menunjukan hubungan tegangan output sensor dengan kecepatan.

\begin{tabular}{ccc} 
Tabel & \multicolumn{3}{l}{ 1. Hubungan Tegangan dan Kecepatan sensor JL-F } \\
\cline { 2 - 3 } No & Kecepatan (m/s) & Tegangan(V) \\
\hline 1 & 1 & 0.17 \\
2 & 2 & 0.33 \\
3 & 3 & 0.5 \\
28 & 28 & 4.67 \\
29 & 29 & 4.83 \\
30 & 30 & 5 \\
\hline
\end{tabular}

Berdasarkan pendekatan hubungan tegangan dan kecepatan, diketahui bahwa untuk melakukan kalibrasi nilai pengukuran nilai tegangan menjadi nilai dengan satuan $\mathrm{m} / \mathrm{s}$ adalah dengan menggunakan persamaan rumus 1 .

$v=6 * U$

dengan $v$ adalah kecepatan angin $(\mathrm{m} / \mathrm{s})$ dan $U$ adalah tegangan output dari sensor [19].

Kemudia telah dilakukan pengujian kalibrasi pada sensor kecepatan angin JL-FS2. Kalibrasi dilakukan dengan menggunakan wind tunnel calibrator type 8420 . Hasil kalibrasi diketahui range error sensor JL-FS2 kurang dari $\pm 0,5 \mathrm{~m} / \mathrm{s}$ (nilai standar error yang diperbolehkan BMKG) [13]. Berdasarkan datasheet alat dan hasil pengujian sensor JL-FS2 pada penelitian sebelumnya diketahui sensor JL-FS2 memiliki akurasi yang masuk kedalam standar BMKG. Atas dasar tersebut sensor JL-FS2 dapat digunakan sebagai sensor pada sistem akuisisi kecepatan angin.
Pengujian sistem dilakukan dengan memastikan sensor anemometer tegangan input sensor masuk dan terbaca oleh mikrokontroler dan data pengukuran dari MQTT broker dapat tersimpan pada database. Untuk Pengujian GUI dilakukan dengan cara mengakses Grafana dari jaringan lokal maupun jaringan publik. Pengujian dianggap berhasil jika aplikasi Grafana dapat diakses dari kedua jaringan tersebut dan data data hasil pengukuran dapat termonitor secara realtime.

\section{Hasil dan Pembahasan}

Pemasangan sensor anemometer dilakukan pada puncak Menara SST dengan menggunakan dudukan yang terbuat dari galvanize dan dilapisi cat anti karat seperti ditujukan Gambar 10. Untuk memudahkan instalasi kabel dari sensor menuju ke mikrokontroler yang berada pada bangunan di sebelah kaki tower. Dudukan sensor anemometer dipasang terminal yang tahan air sehingga air tidak dapat masuk kedalam terminal. Bahan galvanize digunakan agar dudukan atau bracket sensor dapat bertahan lama dan terlindungi dari karat.

\subsection{Pengujian}

Pengujian pertama dilakukan dengan memastikan data pengukuran dapat tersimpan pada database. Dari hasil pengujian didapatkan data hasil pengukuran berhasil tersimpan pada database seperti ditujukan pada Gambar 11. Berdasarkan hasil pengujian tersebut diketahui bahwa sistem akuisisi telah berfungsi dan dapat dilakukan proses selanjutnya yaitu proses pengumpulan data.

Pengujian kedua dilakukan dengan memastikan server Grafana dapat diakses dari jaringan lokal dan juga jaringan publik serta data pengukuran dapat termonitor secara realtime.

Dari hasil pengujian didapatkan server Grafana dapat diakses dari jaringan lokal maupun jaringan publik. Data pengukuran kecepatan angin dapat termonitor secara realtime seperti ditujukan Gambar 12.

\subsection{Pengumpulan Data Pengukuran}

Pengukuran kecepatan angin dilakukan mulai tanggal 06 Februari 2021 sampai dengan tanggal 27 Mei 2021. Selama periode tersebut sistem akuisisi berhasil mengumpulkan data pengukuran kecepatan angin sebanyak 5.501.689 data. Gambar 13 menunjukan grafik pengukuran kecepatan angin selama periode tersebut. Pada grafik tersebut dapat dilihat kecepatan angin ratarata pada menara SST adalah 3,03 m/s dan kecepatan maksimal angin sempat menyentuh angka $20,48 \mathrm{~m} / \mathrm{s}$ pada bulan April 2021. 


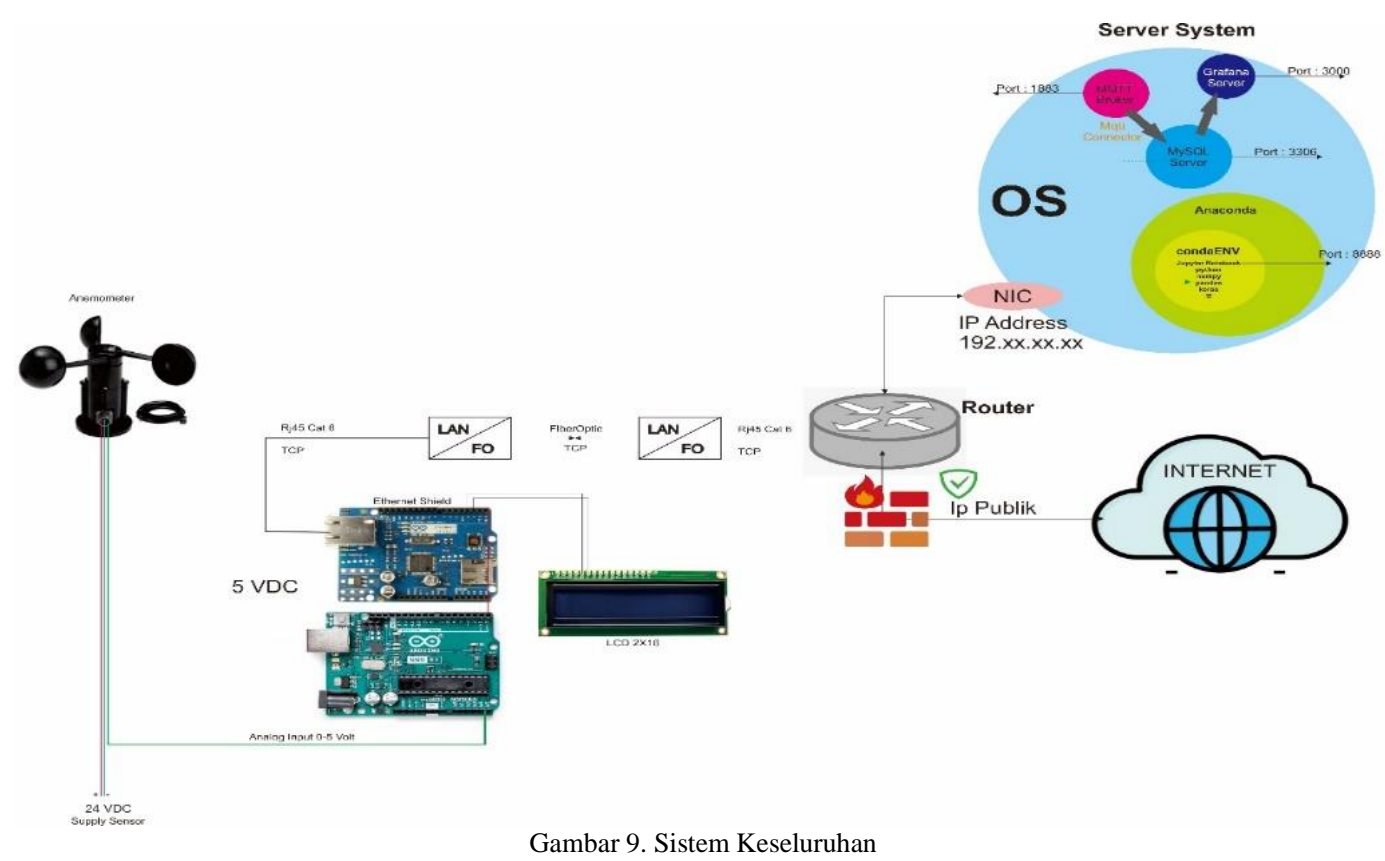

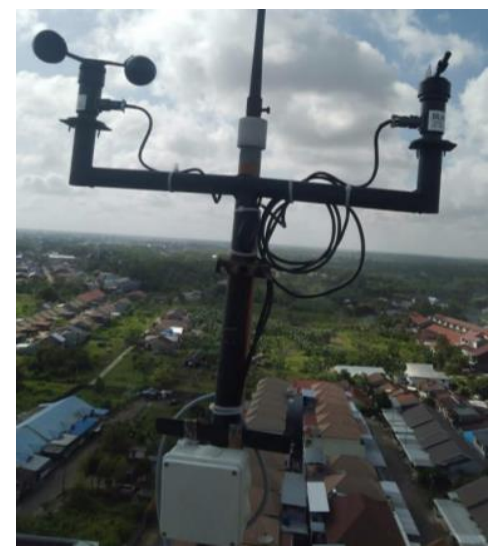

Gambar 10. Sensor Anemometer pada Puncak Menara SST
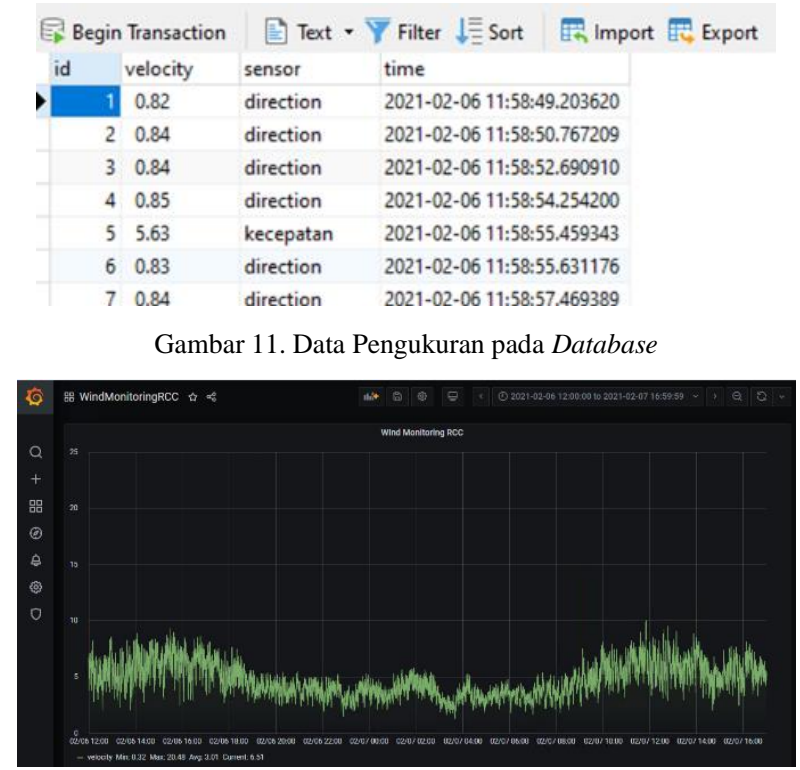

Gambar 12. Pengujian Akses Grafana
Tabel 2. Hasil Akuisisi Data Pengukuran Angin Bulanan

\begin{tabular}{lccc}
\hline No & Bulan & Jumlah Data & Kec.Rata-Rata $(\mathrm{m} / \mathrm{s}$ \\
\hline 1 & Februari & 1.226 .585 & 3.97 \\
2 & Maret & 1.393 .803 & 2.87 \\
3 & April & 1.410 .426 & 2.82 \\
4 & Mei & 1.470 .875 & 2.58 \\
\hline
\end{tabular}

Tabel 2 menunjukan hasil akuisisi data kecepatan angin tiap bulan, diketahui data akuisisi terbanyak terjadi pada bulan Mei 2021. Dan kecepatan rata-rata angin bulanan terbesar terjadi pada bulan Februari 2021.

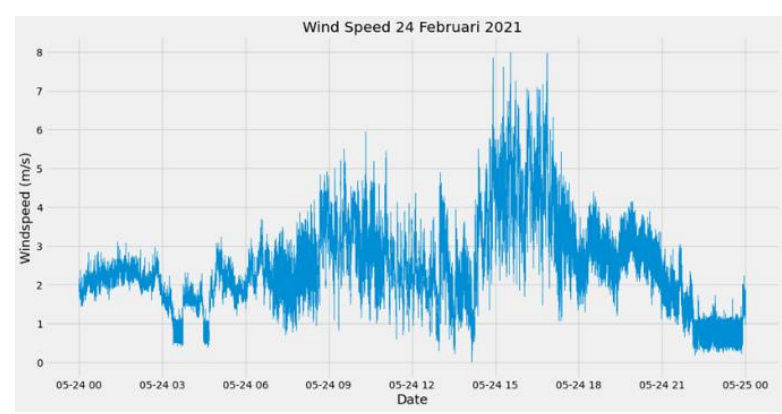

Gambar 14. Profil kecepatan angin tanggal 24 Februari 2021

Berdasarkan pengukuran kecepatan angin diketahui kecepatan rata-rata angin tertinggi terjadi pada tanggal 24 Februari 2021 dimana nilai kecepatan rata-rata angin sebesar 4,58 m/s. Tabel 3 menunjukan data kecepatan angin rata-rata tiap jam pada tanggal 24 Februari 2021. Dapat dilihat grafik kecepatan angin harian pada Gambar 14. Kecepatan angin mulai meningkat dari jam 06.00 WIB sampai puncaknya jam 16.00 WIB, setelah itu kecepatan angin mulai menurun. Dimana titik terendah kecepatan angin berkisar pada jam 22.00 WIB.

DOI: https://doi.org/10.29207/resti.v5i4.3307

Lisensi: Creative Commons Attribution 4.0 International (CC BY 4.0) 


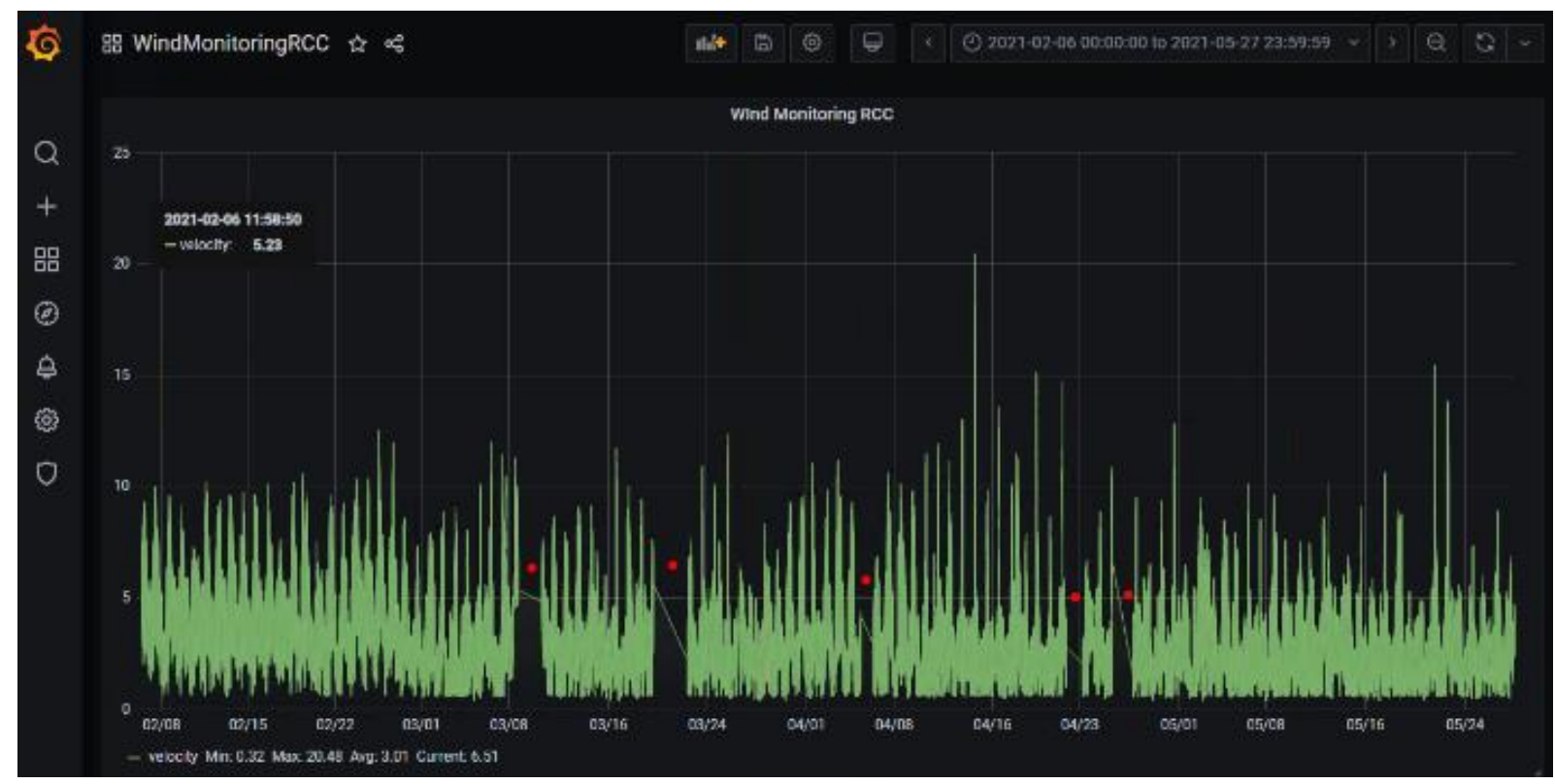

Gambar 13. Grafik Pengukuran Kecepatan Angin Periode 06 Februari s/d 27 Mei 2021.

Tabel 3. Kecepatan Rata-Rata Angin per-Jam 24 februari 2021

\begin{tabular}{lcc}
\hline No & Jam & Kec.Rata-Rata $(\mathrm{m} / \mathrm{s})$ \\
\hline 1 & $01: 00$ & 4.32 \\
2 & $02: 00$ & 4.99 \\
3 & $03: 00$ & 4.40 \\
4 & $04: 00$ & 3.07 \\
5 & $05: 00$ & 3.04 \\
6 & $06: 00$ & 2.34 \\
7 & $07: 00$ & 3.58 \\
8 & $07: 00$ & 3.97 \\
9 & $09: 00$ & 5.35 \\
10 & $10: 00$ & 4.73 \\
11 & $11: 00$ & 3.40 \\
12 & $12: 00$ & 5.00 \\
13 & $13: 00$ & 5.18 \\
14 & $14: 00$ & 3.77 \\
15 & $15: 00$ & 5.21 \\
16 & $16: 00$ & 6.21 \\
17 & $17: 00$ & 6.84 \\
18 & $18: 00$ & 4.87 \\
19 & $19: 00$ & 4.90 \\
20 & $20: 00$ & 4.88 \\
21 & $21: 00$ & 4.81 \\
22 & $22: 00$ & 5.40 \\
23 & $23: 00$ & 4.52 \\
24 & $24: 00$ & 3.81 \\
\hline
\end{tabular}

\subsection{Pemantauan Sistem}

Selama proses pengukuran kecepatan angin berlangsung terjadi 5 kali kegagalan sistem yang mengakibatkan data pengukuran kecepatan angin tidak tersimpan pada database. Titik merah pada Gambar 13 menunjukan interval waktu kegagalan pengukuran data pada database.

Kegagalan sistem terjadi disebabkan oleh beberapa faktor diantaranya karena aplikasi MySQL Connector yang digunakan untuk melakukan fungsi insert database berhenti beroperasi jika server di-restart dan aplikasi tersebut tidak berjalan secara automatis ketika komputer bekerja kembali. Selanjutnya kegagalan terjadi akibat hang pada perangkat alat konverter FO to LAN. Selama proses pemantauan restart perangkat konverter FO to LAN merupakan tindakan yang dilakukan jika perangkat mengalami hang.

\section{Kesimpulan}

Desain Sistem Akuisisi Kecepatan Angin berbasis IoT pada Menara SST berhasil mengumpulkan Data kecepatan angin dari tanggal 06 Februari 2021 sampai dengan 27 Mei 2021 sebanyak 5.501.689 data pengukuran dengan interval waktu 1-2 detik. Kecepatan rata-rata angin pada tower komunikasi selama proses pengukuran adalah $3,03 \mathrm{~m} / \mathrm{s}$ dan kecepatan rata-rata harian tertinggi terjadi pada tanggal 24 Februari 2021.

Dalam proses pengukuran terjadi beberapa kali kegagalan yang mengakibatkan hasil pengukuran kecepatan angin tidak dapat tersimpan kedalam database sehingga perlu dibuatkan sistem autorun pada server untuk menjalankan aplikasi MySQL Connector jika komputer server mengalami restart. Selanjutnya pada panel Arduino dan Konverter FO to LAN perlu ditambah sistem pendingin agar suhu modul Arduino dan peralatan komunikasi lainnya tetap terjaga. Selanjutnya Untuk akurasi data pengukuran yang memiliki kekuatan hukum, kalibrasi alat dilakukan oleh badan yang terakreditasi.

\section{Ucapan Terimakasih}

Terimakasih kepada jajaran manajemen dan pegawai PT PLN (Persero) UP3B Kalbar yang telah mengizinkan dan membantu pelaksanaan proses penelitian ini.

\section{Daftar Rujukan}

[1] BPPT, Indonesia Energy Outlook 2019: The Impact of Increased Utilization of New and Renewable Energy on the 
National Economy. 2019.

[2] A. Ihwan and I. Sota, "Kajian Potensi Energi Angin untuk Perencanaan Sistem Konversi Energi Angin (SKEA) di Kota Pontianak," J. Fis. FLUX, vol. 7, no. 2, pp. 130-140, 2010.

[3] Z. Ulva and A. Ihwan, "Potensi Energi Listrik Tenaga Angin Di Kota Pontianak," Prism. Fis., vol. VI, no. 01, pp. 22-25, 2018.

[4] I. R. Utami, M. I. Jumarang, and Apriansyah, "Perhitungan potensi energi angin di kalimantan barat," Prism. Fis., vol. 66, no. 1, pp. 65-69, 2018.

[5] "Data Base Transceiver Station (BTS) Telkomsel di Kota Pontianak Tahun 2017 - Datasets - SATU DATA PROVINSI KALIMANTAN BARAT." http://data.kalbarprov.go.id/dataset/bts-telkomsel-di-kotapontianak-tahun-2017 (accessed Jul. 16, 2021).

[6] Y. Efendi, "Internet Of Things (Iot) Sistem Pengendalian Lampu Menggunakan Raspberry Pi Berbasis Mobile," J. Ilm. Ilmu Komput. Fak. Ilmu Komput. Univ. Al Asyariah Mandar, vol. 4, no. 2, pp. 21-27, Sep. 2018, doi: 10.35329/JIIK.V4I2.41.

[7] K. Chooruang and K. Meekul, "Design of an IoT Energy Monitoring System,” Int. Conf. ICT Knowl. Eng., vol. 2018Novem, pp. 48-51, 2019, doi: 10.1109/ICTKE.2018.8612412.

[8] F. Faisal, E. Mardianto, and T. Muzakir, "Penerapan Raspberry Pi untuk Pengukuran Jarak Jauh terhadap Potensi Energi Angin," J. Vokasi, pp. 84-89, 2018, [Online]. Available: http://ejurnal.polnep.ac.id/index.php/vokasi/article/view/137.

[9] V. Siswanto and E. Edidas, "Prototype Station Informasi Cuaca Berbasis IOT Wemos di ESP8266," Voteteknika (Vocational Tek. Elektron. dan Inform., vol. 9, no. 2, p. 71, 2021, doi: 10.24036/voteteknika.v9i2.111651.

[10] R. K. M. Math and N. V. Dharwadkar, "IoT Based low-cost weather station and monitoring system for precision agriculture in India," Proc. Int. Conf. I-SMAC (IoT Soc. Mobile, Anal. Cloud), I-SMAC 2018, pp. 81-86, 2019, doi: 10.1109/ISMAC.2018.8653749.

[11] C. Rakhmad Handoko, A. Zuhri Arfianto, and M. Khoirul Hasin, "Perangkat Informasi Kecepatan Angin Berbasis Motor [20] DC dan Jaringan Internet of Things."

[12] R. Prabowo, A. Muid, and R. Adriat, "Rancang Bangun Alat Pengukur Kecepatan Angin,” Prism. Fis., vol. 6, no. 2, pp. 94100, Apr. 2018, doi: 10.26418/PF.V6I2.25260.

[13] R. Simanullang, S. Soekirno, and H. A. Larassari, "Design and analysis of air quality monitoring system PM 10 and PM 2.5 integrated with weather parameters (a case study on Margonda Raya street Depok) Recent citations A CMOS Hall sensor modeling with readout circuitry and microcontroller processing for magnetic detection Hua Fan et al Design and analysis of air quality monitoring system PM10 and PM2.5 integrated with weather parameters (a case study on Margonda Raya street Depok)," Meas. Metrol. J. Phys. Conf. Ser., vol. 1528, p. 12053, 2020, doi: 10.1088/1742-6596/1528/1/012053.

[14] Y.-N. Lin, S.-K. Wang, G.-J. Chiou, C.-Y. Yang, V. R. L Shen, and Z. Yang Su, "Development and Veriication of an IoTEnabled Air Quality Monitoring System Based on Petri Nets," doi: 10.21203/rs.3.rs-627459/v1.

[15] H. A. Kusuma, R. Anjasmara, T. Suhendra, H. Yunianto, and S. Nugraha, "An IoT Based Coastal Weather and Air Quality Monitoring Using GSM Technology," J. Phys. Conf. Ser., vol. 1501 , no. 1, p. 012004, Mar. 2020, doi: 10.1088/17426596/1501/1/012004.

[16] Z. Y. Su, Y. N. Lin, and V. R. L. Shen, "Intelligent Environmental Monitoring System based on LoRa Long Range Technology," 2019 IEEE Eurasia Conf. IOT, Commun. Eng. ECICE 2019, pp. 354-357, 2019, doi: 10.1109/ECICE47484.2019.8942778.

[17] C. A. Vargas Salgado, L. Montuori, P. Bastida Molina, and D. Alfonso Solar, "Arduino-based prototype to estimate heat stress indices in urban environments," Proc. 5th CARPE Conf. Horiz. Eur. beyond, pp. 173-182, Oct. 2019, doi: 10.4995/CARPE2019.2019.10199.

[18] P. Ihsan and T. Rahayu, "ANALISIS KESTABILAN PONDASI PADA MENARA TELEKOMUNIKASI," Konstruksia, vol. 8, no. 2, pp. 53-70, Oct. 2017, doi: 10.24853/JK.8.2.53-70.

[19] "Wind_Speed_Sensor_Voltage_Type_05V_SKU_SEN0170-DFRobot." https://wiki.dfrobot.com/Wind_Speed_Sensor_Voltage_Type_ 0-5V_SKU_SEN0170 (accessed Jul. 17, 2021).

[20] "Getting started Grafana Labs." https://grafana.com/docs/grafana/latest/getting-started/ (accessed Jul. 17, 2021).

[21] "FAQ." https://mqtt.org/faq/ (accessed Jul. 17, 2021).

[22] "Eclipse Mosquitto." http://mosquitto.org/ (accessed Jul. 17, 2021).

DOI: https://doi.org/10.29207/resti.v5i4.3307 